\title{
Analyzing the Dynamic Characteristics of Milling Tool Using Finite Element Method and Receptance Coupling Method
}

\author{
Jui-Pin Hung \\ Graduate Institute of Precision Manufacturing \\ National Chin-Yi University of Technology \\ Taichung, Taiwan \\ hungjp@ncut.edu.tw
}

Kung-Da Wu

Graduate Institute of Precision Manufacturing

National Chin-Yi University of Technology

Taichung, Taiwan

ffi85236@hotmail.com

\author{
Wei-Zhu Lin \\ Graduate Institute of Precision Manufacturing \\ National Chin-Yi University of Technology \\ Taichung, Taiwan \\ WeiJun@itri.org.tw \\ Wei-Cheng Shih \\ Graduate Institute of Precision Manufacturing \\ National Chin-Yi University of Technology \\ Taichung, Taiwan \\ z91150@hotmail.com
}

\begin{abstract}
This study aims to investigate the dynamic characteristics of a milling machine with different head stocks by using finite element (FE) method and receptance coupling analysis (RCA). For this purpose, five full finite element machine models, including vertical column, reformed head stock and feeding mechanism were created. With these models, the tool point frequency response functions were directly predicted. Another approach was the application of the receptance coupling method, in which the frequency response of the assembly milling tool was calculated from the receptance components of the individual substructures through the coupling operation with the interfaces of the feeding mechanism. Results show that a whole machine model with reformed stock has superior dynamic behavior when compared with the original design, by an increment of $10 \%$ in the dynamic stiffness. The receptance coupling method was verified to show an accurate prediction of the frequency response functions of the spindle tool when compared with the results obtained from the full FE models. Overall, the proposed methodology can help the designer to efficiently and accurately develop the machine tool structure with excellent mechanical performance.
\end{abstract}

Keywords-frequency response function; receptance coupling analysis method; Spindle tooling system

\section{INTRODUCTION}

Virtual machine tool technology has been widely used in the design of innovative machine tools of various configurations [1]. Basically, the kernel of the virtual machine tools was developed based on the integration of kinematics, structural dynamics, machining mechanics and the motion control of the machining dynamic system, which can help the designer to evaluate the motion precision and machining performance by means of implementation of the structural optimization and virtual machining into virtual machine tool technology $[2,3]$. On other hand, the machining performance could be affected by poor situations due to the tool chattering during chip generation process. As a well-recognized fact, the machining performance is determined by the frequency characteristics of the machine tool structure and the dynamics of the cutting process [4-8], while the dynamic behavior of a machine tool system is determined by the machine frame structure, feeding and guiding system, and the spindle-tool holder-tool module, in particular the interaction of the vibration coupled with fundamental modes of the machine tool structure [9-10].

In general, improvement of the dynamic characteristics can be achieved in an easier way through the optimization of the feeding system with different specifications, instead of the modification of the machine frame structures. The main components and their properties that affect the static and dynamic characteristics of the milling tool system have been clarified, including the machine frame structure, linear components, feeding mechanism configuration, and spindle tool holder/tool modulus. Besides, detail considerations of the selection of the spindle tool unit and the linear components in feeding mechanism are important for the design of a milling machine system with the desired performance $[11,12]$. In an attempt to propose the improvement strategy of the machine tool system by maximizing machining stability, different approaches were developed for machine manufacturing to improve machine productivity and energy efficiency. The strategies include the use of new materials for the constructions of machine structures and design methodologies for machine frame configurations [13-17]. Optimization criteria of the machine tool design have been carried out by incorporating the dynamics of machine tool with the consideration of machining stability in process [18]. 
On the other hand, at design phase, the prediction of dynamic behavior of the spindle tooling system can be a complicated task when considering the change of the machine frame structure or structure configuration or the change of the linear components specifications. A number of significant developments have been completed to improve the tool and holder modeling techniques and understand the contact stiffness and damping behavior at connecting joints [19-26]. For example, authors in $[20,21]$ implemented the receptance coupling theory of structural dynamics by using experimentally obtained spindle-holder dynamics and analytically obtained tool dynamics for the prediction of the frequency response functions (FRFs). Authors in [23] and [24] also analyzed the effects on the FRFs of spindle-holder and tool-holder interfaces respectively and suggested a fast and accurate approach for the identification of connection parameters. Authors in [25] investigated the influence of overhang length of cutter on the frequency responses of spindle tool based on the receptance coupling operation method.

The aim of this study is to investigate the effect of reformed spindle head stock on the dynamic performance of a machine tooling system by FE method. Besides, considering analysis efficiency, frequency based coupling method was employed to predict the tool point FRFs by coupling the feeding mechanism between head stock and the vertical column structure. Through this investigation, the influence of the design configuration and specification of spindle tool unit can be clarified. Also, the enhancement of the dynamic characteristics of machine tool before and after improvement can be quantified effectively. It is believed that the proposed methodology can help manufacturesr to develop a machine tool structure with excellent mechanical performance.

\section{FINITE ELEMENT MODELING OF A MILLING MACHINE}

\section{A. Model Description}

Figure 1 illustrates the main components of a vertical milling machine, which includes a vertical column structure, spindle head stock, feeding mechanism and spindle tool module. To evaluate the dynamic behaviors of the milling machine, a three dimensional CAD model was created by using SOLIDWORKS software and then imported into the ANSYS Workbench software to perform the simulation. The FEM machine structure is shown in Figure 1. Each structural component of the system was meshed using an eight-node hexahedron and ten-node tetrahedral elements in a total of 130,850 elements and 451,533 nodes. Regarding the linear components in the feeding mechanism of the spindle head stock, the ball screw and the linear guide modulus were included in the FE model since they demonstrated affecting the mechanical behaviors of the spindle heads [9, 10]. Following the modeling method [9], the rolling interfaces between rolling balls and raceways were simulated as surface-surface contact elements with adequate contact stiffness. In this study, the rigidity of the linear guides is rated as $1000 \mathrm{~N} / \mu \mathrm{m}$ and $3000 \mathrm{~N} / \mu \mathrm{m}$ in horizontal and vertical directions respectively. The material properties of the structure components are $\rho=7860 \mathrm{~kg} / \mathrm{m}^{3}$, Young's modulus E=200GPa and Poisson's ratio $\mu=0.3$. Modal and harmonic analysis were respectively conducted to assess the vibration modal shapes and frequency response functions. In FE governing equation for harmonic analysis, a modal damping ratio of $2.5 \%$ was assumed for spindle dominant vibration mode. The frequency responses can then be predicted by applying a unit force at the end of the tool holder of the spindle.
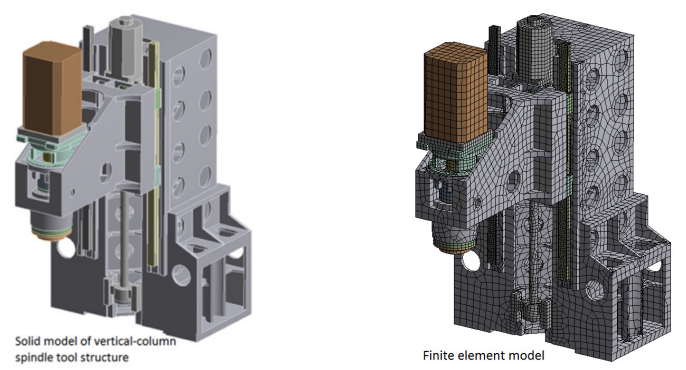

Fig. 1. Solid model and FE model of the vertical spindle tool system

\section{B. Vibration Modes and Frequency Response Function}

According to the results of modal and harmonic analysis, the fundamental vibration modes of the vertical column spindle tool are illustrated in Figure 2. These modes are associated with the vibration of the machine frame structure. For example, the first mode at about $43 \mathrm{~Hz}$ is the twisting vibration of the vertical structure about the $\mathrm{Z}$ axis and the second mode around $107 \mathrm{~Hz}$ is associated with the yawing vibration of the spindle head, which may cause a great deformation of the spindle tool. The fourth mode is the yawing motion of the spindle head stock on the vertical column about the $\mathrm{Y}$ axis. Figure 3 shows the frequency response function of the spindle tool subjected to unit force at spindle nose, which is expressed in terms of the dynamic compliance at the tool end as a function of frequency. The frequencies ranging from 0 to $500 \mathrm{~Hz}$ are mainly dominated by the structure vibrations. It is also found that maximum compliance occurs at mode 1 and 2 around 43 and $107 \mathrm{~Hz}$. The maximum compliance is about $0.285 \mathrm{um} / \mathrm{N}$ and the maximum negative real part is about $0.14 \mathrm{um} / \mathrm{N}$.
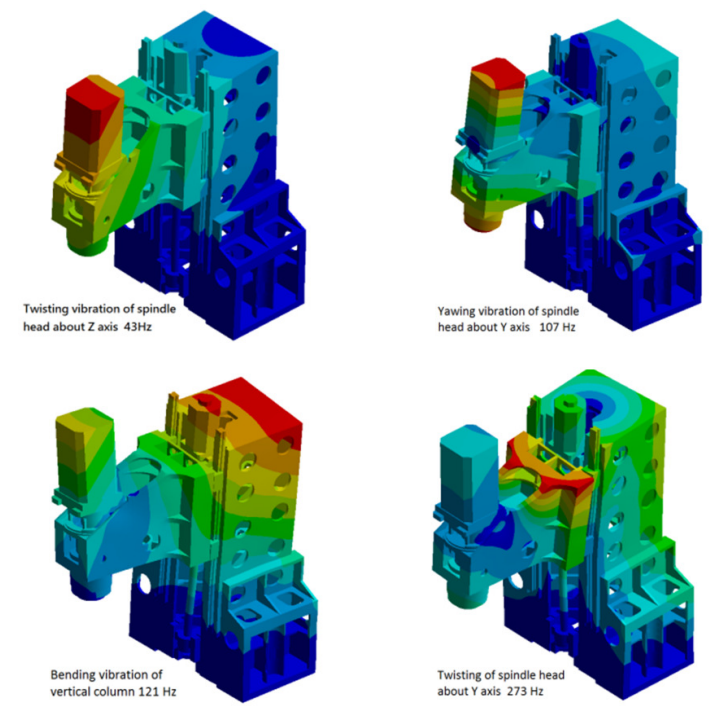

Fig. 2. Fundamental modal shapes of vertical spindle tool system. 

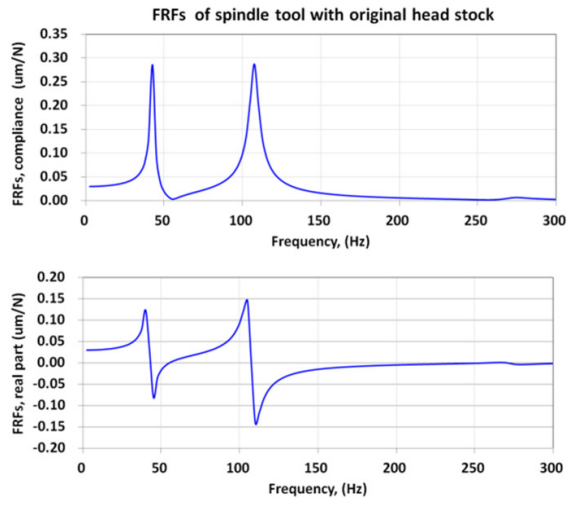

Fig. 3. Frequency response function of the vertical spindle tool system

\section{Structure Effect of Spindle Head Stock}

\section{1) Reformed Head Stocks}

Following the analysis results of the whole milling machine, the structure geometry of the spindle head was redesigned to enhance the stiffness of the spindle tool. The head stocks are shown in Figure 4 with different stiffened ribs of different size. The weights of the 5 head stocks are listed in Table I. To examine the effect of the spindle head structure on the dynamic compliances, $4 \mathrm{FE}$ models of the milling machine with different reformed head stock were respectively created following the previous method. Harmonic analysis was conducted on each whole machine model to assess the FRFs for comparison.

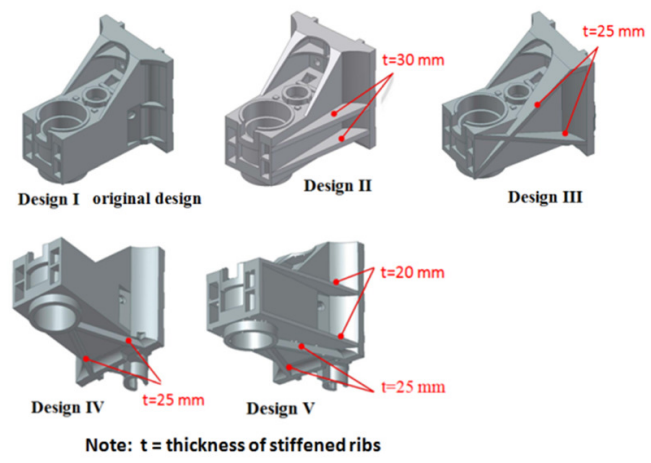

Fig. 4. Reformed head stocks with different stiffened ribs of different size.

TABLE I. HEAD STOCKS COMPARISON

\begin{tabular}{|c|c|}
\hline Spindle head stock model & Weight (kg) \\
\hline Original model I & 272 \\
\hline Stiffened model II & 308 \\
\hline Stiffened model III & 298 \\
\hline Stiffened model IV & 297 \\
\hline Stiffened model V & 308 \\
\hline
\end{tabular}

\section{2) FRFs predicted by Full FE Models}

The tool point FRFs predicted from the vertical spindle tool model with different head stocks are illustrated in Figure 5. As observed, the spindle tool shows similar vibration behaviors with two dominant modes at lower frequency ranges although it is equipped with head stocks of different design. As mentioned above, the first mode around $43 \mathrm{~Hz}$ is mainly the twisting vibration of the head stock and vertical column about the $\mathrm{Z}$ axis. So it was found not to vary when the head stock changed. However, the second mode around $102-107 \mathrm{~Hz}$ is the yawing vibration of the head stock, which is related to the yawing motion of the linear guides on the vertical column [9]. It is noted that the frequency and compliance of this mode vary due to the change of the head stock. This clearly implies the effect of the spindle stock on the dominant vibration of the vertical spindle head. Maximum compliances of the five spindle tool models are $0.287 \mathrm{um} / \mathrm{N}$ at $107 \mathrm{~Hz}$ (original stock I), $0.263 \mathrm{um} / \mathrm{N}$ at $103 \mathrm{~Hz}$ (stock II), $0.259 \mathrm{um} / \mathrm{N}$ at $105 \mathrm{~Hz}$ (stock III), $0.270 \mathrm{um} / \mathrm{N}$ at $103 \mathrm{~Hz}$ (stock IV) and $0.267 \mathrm{um} / \mathrm{N}$ at $102 \mathrm{~Hz}$ (stock V), respectively. Actually, differences in the frequency and compliance among these spindle tool systems are not so apparent, but the spindle with third stock indeed improve the structure performance, about $10 \%$ increment in the dynamic stiffness compared with the original one. As shown in Figure 5, there are two vibration modes with significant amplitudes around $43 \mathrm{~Hz}$ and $107 \mathrm{~Hz}$, in which the one at $107 \mathrm{~Hz}$ was selected as the base for evaluation of the machining stability since it is associated with the yawing vibration of spindle head and both frequency and amplitude are affected to different extent by the reformed head. According to machining mechanics [7], the machining stability is determined by the maximum value of negative real part of the FRF. Therefore, the difference of the machining stability of spindle tool with different head stocks can be assessed by comparing the real parts of the FRFs. Based on the real part of the predicted FRFs, the machining stability of the milling tool can be expected to be increased by about $10 \%$ when the head stock is reformed to the third design from original one.
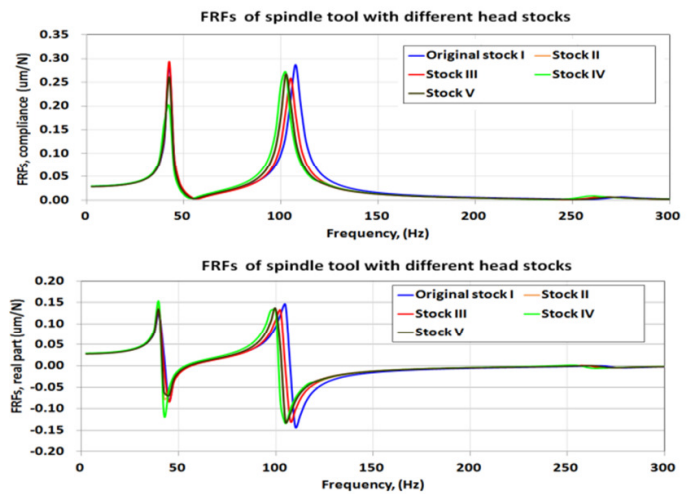

Fig. 5. Predicted tool point frequency response functions of vertical spindle tool models with different head stocks.

\section{FRF PREDICTION BY RSCA}

\section{A. Basic Theory of Receptance Coupling Method (RCA)}

In this section, receptance coupling substructure analysis method (RCSA) was used to predict the FRFs of the spindle tool with different head stocks, instead of the FE prediction with whole machine models. The vertical column and the feeding mechanism remained in the structure, only the spindle 
head was reformed with stiffened ribs on stock housing. The vertical column spindle tool system (assembled structure $\mathrm{AB}$ ) can be regarded as an assemble of the spindle head (substructure A) and the vertical column (substructure B) coupled by linear guide modules (joints) as shown in Figure 6 .

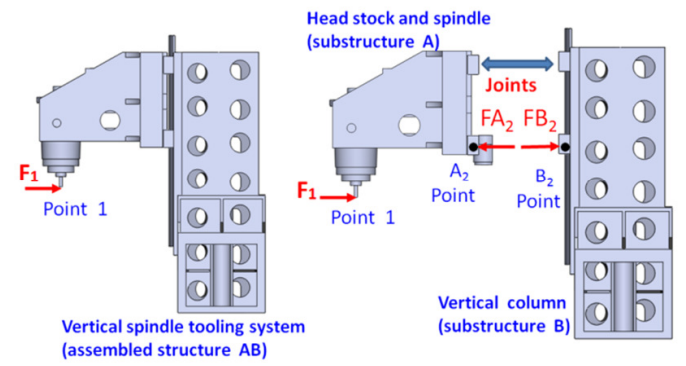

Fig. 6. Schematic of the coupling of substructures, vertical column and spindle head stock.

For substructure $A$, the relationship between the displacements of points $1, A_{2}$ and forces $F_{1}, F A_{2}$ can be expressed as:

$$
\left\{\begin{array}{c}
X_{1} \\
X A_{2}
\end{array}\right\}=\left[\begin{array}{ll}
H A_{11} & H A_{12} \\
H A_{21} & H A_{22}
\end{array}\right]\left\{\begin{array}{c}
F_{1} \\
F A_{2}
\end{array}\right\}
$$

where $X_{1}$ and $X A_{2}$ are the displacements at point 1 and $A_{2}$ on substructure A. $F_{1}$ and $F A_{2}$ are the forces applied at point 1 and $\mathrm{A}_{2} . H A_{11}$ and $H A_{12}$ are the responses of the point 1 due to the excitation at point 1 and point 2 respectively. So the term $H_{\mathrm{ij}}$ represents the response of the point $i$ caused by the excitation at point $j$, normally called the compliance function of the substructure A.

For substructure $B$, the relationship between the displacement of point $B_{2}$ and force $F B_{2}$ is:

$$
\left\{X B_{2}\right\}=\left[H B_{22}\right]\left\{F B_{2}\right\}
$$

where $X B_{2}$ is the displacement at point $B_{2}$ on substructure B. $F B_{2}$ is force applied at point $B_{2} . H B_{22}$ represents the compliance function of the substructure $B$. have:

When substructure A is combined with substructure B, we

$$
F_{2}=F A_{2}+F B_{2}, \quad X_{2}=X A_{2}=X B_{2}
$$

The displacement of point 1 caused by force $F_{1}$ can be obtained as follows:

$$
G_{11}=\frac{X_{1}}{F_{1}}=H A_{11}-H A_{12}\left(H A_{22}+H B_{22}\right)^{-1} H A_{21}(4)
$$

where $H_{2}=H A_{22}+H B_{22}$ represents the coupled term of the substructure $\mathrm{A}$ and substructure $\mathrm{B}$, and $G_{11}$ is the frequency response function of the assembled structure due to the excitation $F_{1}$.

Actually, the displacement components measured at each point on the substructures or assembled structure include the linear translation displacement $(x)$ and the angular displacement $(\theta)$, which are caused by the force $\left(f_{l}\right)$ and moment $\left(M_{1}\right)$, respectively. The generalized relationship between the displacement vector $\left\{X_{1}\right\}$ and force vector $\left\{F_{1}\right\}$ can be expressed as follows:

$$
\left\{X_{1}\right\}=\left\{\begin{array}{l}
\mathrm{x}_{1} \\
\theta_{1}
\end{array}\right\} ;\left\{F_{1}\right\}=\left\{\begin{array}{l}
f_{1} \\
M_{1}
\end{array}\right\}
$$

Taking the head stock (substructure A) as an example, we have the following expressions:

$$
\begin{array}{r}
\left\{\begin{array}{l}
x_{1} \\
\theta_{l}
\end{array}\right\}=\left[\mathrm{HA}_{11}\right]\left\{\begin{array}{c}
f_{l} \\
M_{l}
\end{array}\right\}=\left[\begin{array}{ll}
H a_{11} & L a_{11} \\
N a_{11} & P a_{11}
\end{array}\right]_{A}\left\{\begin{array}{c}
f_{l} \\
M_{l}
\end{array}\right\} \\
H a_{11}=\frac{x_{1}}{f_{1}}, L a_{11}=\frac{x_{1}}{M_{1}} ; N a_{11}=\frac{\theta_{1}}{f_{1}} ; P a_{11}=\frac{\theta_{1}}{M_{1}}
\end{array}
$$

where $\left[\mathrm{HA}_{11}\right]$ represents the frequency responses matrix or component receptance matrix of substructure A. Similar expressions are valid for the vertical column (substructure B) and the vertical spindle tool system (assembled structure AB).

Since the vertical column and spindle head stock are assembled together by the feeding mechanism, there is an elastic bonding between the two substructures. Also, it is noted that the linear guide modules show important influences on the dynamic characteristics of the milling machine [9]. Considering this elastic joint, the coupled effect should be included in (4) through the interface characteristics matrix [26]:

$\left[K_{s}\right]=\left[\begin{array}{cc}K_{x f}+i w C_{x f} & K_{\theta f}+i w C_{\theta f} \\ K_{x M}+i w C_{x M} & K_{\theta M}+i w C_{\theta M}\end{array}\right]$

where $K_{x f}, K_{\theta f}, K_{x M}$ and $K_{\theta M}$ are the normal and rotational stiffness of the interface against the transverse force and moment. $C_{x f}, C_{\theta f}, C_{x M}$ and $C_{\theta M}$ are the damping coefficients of the interface associated with the normal and rotational degree of freedom, respectively.

\section{B. Coupling Operation of FRFS}

The receptance compliance matrices of spindle head stock and vertical column can be respectively expressed as below:

$$
\begin{aligned}
& {\left[\mathrm{HA}_{\mathrm{ij}}\right]=\left[\begin{array}{ll}
H a_{\mathrm{ij}} & L a_{\mathrm{ij}} \\
N a_{\mathrm{ij}} & P a_{\mathrm{ij}}
\end{array}\right] \quad \mathrm{i}, \mathrm{j}=1,2} \\
& {\left[\mathrm{HB}_{22}\right]=\left[\begin{array}{ll}
H b_{22} & L b_{22} \\
N b_{22} & P b_{22}
\end{array}\right]}
\end{aligned}
$$

Direct or cross compliance components in receptance matrix such as $H a_{\mathrm{ij}}$ and $L a_{\mathrm{ij}}$ can be obtained by conducting harmonic analysis on the FE model of spindle unit and head stocks. These components are then used to derive $N a_{\mathrm{ij}}$ and $P a_{\mathrm{ij}}$ by finite difference approach [20]. Figure 7 shows the FRFs of the $H a_{11}$ and $L a_{11}$, in which $H a_{11}$ is the displacement of the spindle nose under the excitation force $f_{l}$ and $L a_{11}$ is the displacement at mounted position of linear guides with vertical column under the moment $M_{1}$ applied at the end point of tool holder respectively. It is noted that the reformed head stocks with different stiffened ribs have different structure characteristics. Figure 8 shows the FRFs of the $H b_{22}$ and $L b_{22}$, representing the displacements of the vertical column under the excitation force $f_{2}$ and moment $M_{2}$ applied at joints respectively. 

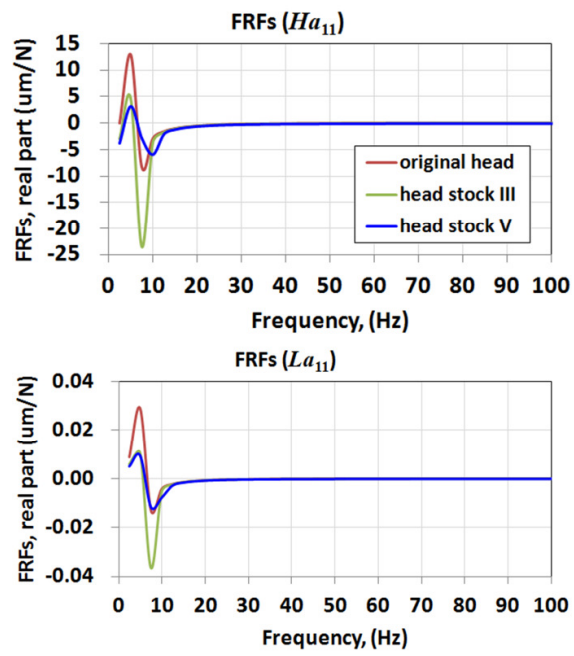

Fig. 7. Frequency reponse functions of the head stocks $\left(H a_{11}\right.$ and $\left.L a_{11}\right)$
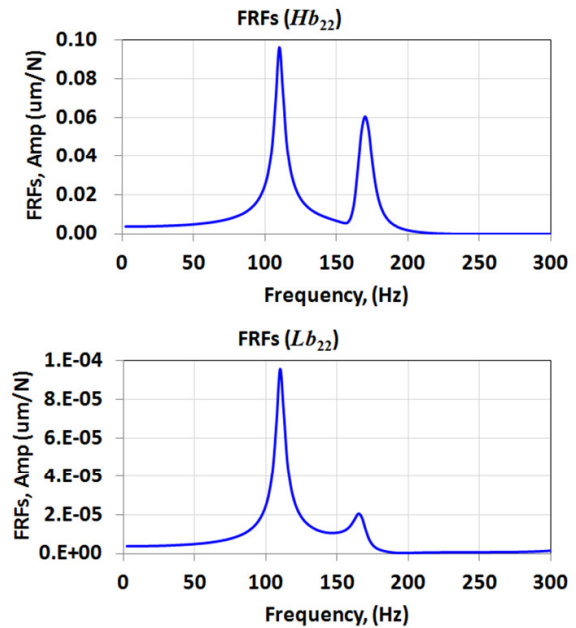

Fig. 8. Frequency reponse functions of the vertical column $\left(H b_{22}\right.$ and $\left.L b_{22}\right)$

According to (4) and (8), the frequency response function at the spindle nose of the whole vertical spindle tool system can be predicted as follows:

$$
\frac{\left\{\mathrm{X}_{1}\right\}}{\left\{\mathrm{F}_{1}\right\}}=\left(\left[H A_{11}\right]-\left[H A_{12}\right] \cdot\left(\left[H A_{22}\right]+\left[H \mathrm{~B}_{22}\right]+\left[\mathrm{K}_{\mathrm{s}}\right]^{-1}\right)^{-1} \cdot\left[H A_{21}\right]\right)(10)
$$

As noted in (10), the interface characteristic matrix $\left[K_{s}\right]$ is the required parameter for the coupling operation. For this, the compliance matrices associated with the vertical spindle tool system with original head stock were input to the operation algorithm and hence the interface properties were identified by inverse coupling operation.

\section{FRF Comparison by FEM and RCSA}

Figure 9 illustrates the frequency response functions predicted by the whole machine models and calculated by RCSA. It can be found that for milling machines with different reformed head stocks, the FRFs calculated by RCSA agree well with the FE predictions for whole machine models.
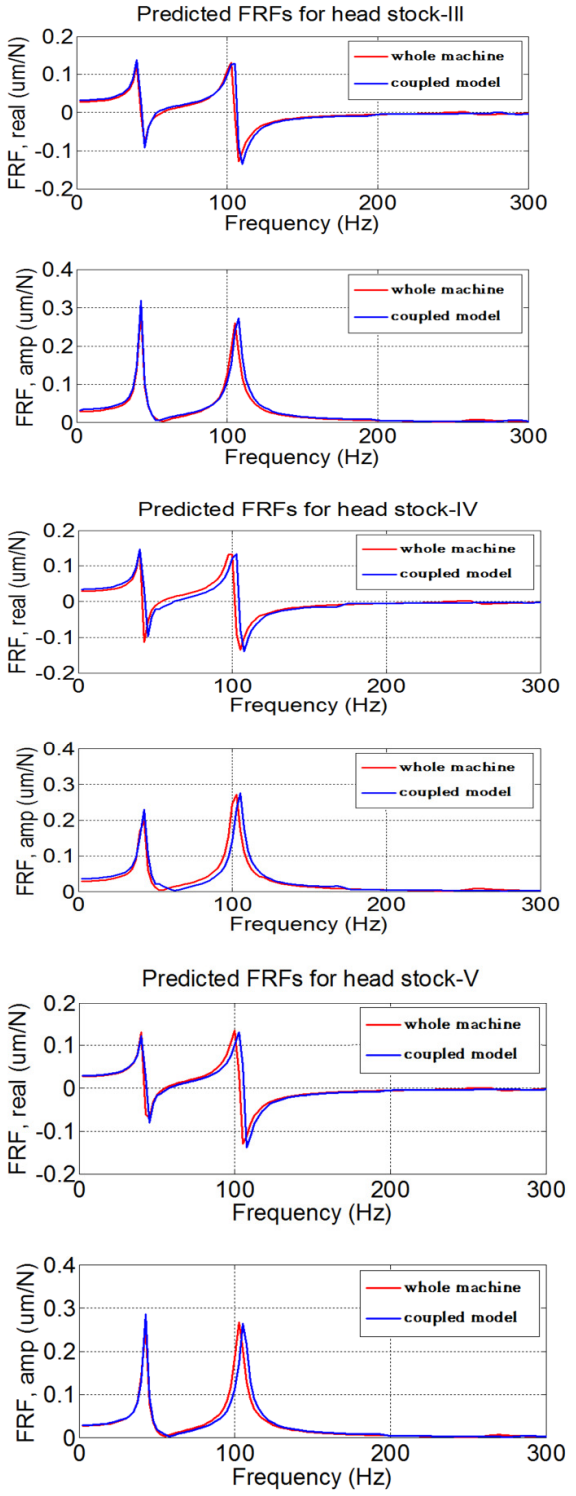

Fig. 9. Comparison of the FRFs predicted by the whole machine model and calculated by receptance coupling method.

It is observed that for the first mode, the predictions of the compliance and frequency by the two approaches are almost the same, irrespective of the type of the reformed head stocks. This is due to the fact that this mode is affected by the linear feeding mechanism. However, for the second mode, there is a slight difference in the predicted FRFs of the 5 machine models between the two methods, with maximum difference of $3.5 \%$. This shows the reformed head stock has a slight influence on the interface characteristics of the coupling joints at the feeding mechanism, causing the prediction errors in coupling operation. Overall, the results of the above analysis indicate that the RCSA in prediction of the FRFs of the assembled structure is an efficient and accurate way in determining the structure performance when attempting to reform the machine tool at design stage. 


\section{CONCLUSION}

In this study, the dynamic characteristics of the spindle tool system were analyzed by employing a full FE model of the machine frame structure and spindle tool unit. The effect of the reformed spindle head stock was also examined through RCSA. The results show that appropriate reformed stocks indeed improve the structure performance, showing about $10 \%$ increment in dynamic stiffness or $10 \%$ reduction in dynamic compliance when compared with the original stock. According to the machining mechanics, the machining stability is determined by the maximum value of negative real part of the FRF. Based on the predicted FRFs, the machining stability of the milling tool can be appropriately increased by reforming the head stock with stiffened ribs. Additionally, RCSA was employed to calculate the frequency responses of the reformed spindle tool system based on the receptance components of vertical column and head stocks by introducing the interface characteristics into coupling operation. As a whole, the proposed methods were verified to show an accurate prediction of the FRFs of the spindle tool for the improvement of the structure configuration.

\section{ACKNOWLEDGMENT}

Authors gratefully acknowledge the support provided by the National Science Council in Taiwan through project number MOST105-2221-E-167-006.

\section{REFERENCES}

[1] Y. Altintas, C. Brecher, M. Weck, S. Witt, "Virtual machine tool", CIRP Annals, Manufacturing Technology, Vol. 54, No. 2, pp. 115-138, 2005

[2] R. Neugebauer, S. Ihlenfeldt, U. Frieß, M. Wabner, S. Rauh, "New highspeed machine tool structure by holistic mechatronic systems design", Procedia CIRP, Vol. 1, pp. 307-312, 2012

[3] F. Alessandro, A. Ascari, "The virtual design of machining centers for HSM: Towards new integrated tools", Mechatronics, Vol. 23, pp. 264278, 2013

[4] J. Tlusty, "Dynamics of high-speed milling", Journal of Engineering for Industry, Vol 108, No. 2, pp. 59-67, 1986

[5] F. Koenisberger, J. Tlusty, Machine Tool Structures-Vol. I: Stability Against Chatter, Pergamon Press, 1967

[6] S. A. Tobias, W. Fishwick, "The chatter of lathe tools under orthogonal cutting conditions", Trans ASME, Vol. 80, pp. 1079-1088, 1958

[7] Y. Altintas, E. Budak, "Analytical prediction of stability lobes in milling", CIRP Annals - Manufacturing Technology, Vol. 44, pp. 357362,1995

[8] E. Budak, Y. Altintas, "Analytical prediction of chatter stability in milling-Part I: general formulation; Part II: application to common milling systems", Journal of Dynamic Systems, Measurement, and Control, Vol. 120, pp. 22-36, 1998

[9] J. P. Hung, Y. L. Lai, C. Y. Lin, T. L. Luo, "Modeling the machining stability of vertical milling machine under the influence of the preloaded linear guide", International Journal of Machine Tools and Manufacture, Vol. 51, No. 9, pp. 731-739, 2011

[10] J. P. Hung, Y. L. Lai, T. L. Luo, "Analysis of the machining stability of a milling machine considering the effect of machine frame structure and spindle bearings: experimental and finite element approaches", International Journal of Advanced Manufacturing Technology, Vol. 68, No. 9, pp. 2393-2405, 2013

[11] Y. Koren, U. Heisel, F. Jovane, T. Moriwaki, G. Pritschow, G. Ulsoy, H. V. Brussel, "Reconfigurable manufacturing systems", CIRP Annals, Vol. 48, No. 2, pp. 527-540, 1999
[12] Y. Koren, A. G. Ulsoy, Reconfigurable Manufacturing System Having a Production Capacity Method for Designing Same and Method For Changing its Production Capacity, US Patent US6349237B1, 2002

[13] T. C. Chen, Y. J. Chen, M. H. Hung, J. P. Hung, "Design analysis of machine tool structure with artificial granite material", Advances in Mechanical Engineering, Vol. 8, No. 7, pp. 1-14, 2016

[14] L. Kroll, P. Blau, M. Wabner, U. Frieß, J. Eulitz, M. Klarner, "Lightweight components for energy-efficient machine tools", CIRP Journal of Manufacturing Science and Technology, Vol. 4, No.2, pp. $148-160,2011$

[15] J. J. Zulaika, F. J. Campa, L. N. L. D. Lacalle, "An integrated processmachine approach for designing productive and lightweight milling machines", International Journal of Machine Tools and Manufacture, Vol. 51, pp. 591-604, 2011

[16] A. Bustillo, L. M. Plaza, M. Rodriguez, "New Strategy for the optimal design and manufacture of high performance milling heads", Revista de Metalurgia, Vol. 47, No. 6, pp. 462-476, 2011

[17] A. Bustillo, I. Oleaga, J. J. Zulaika, N. Loix, "New methodology for the design of ultra-light structural components for machine-tools", International Journal of Computer Integrated Manufacturing, Vol. 28, No. 4, pp. 339-352, 2015

[18] D. Huo, K. Cheng, F. Wardle, "A holistic integrated dynamic design and modelling approach applied to the development of ultraprecision micromilling machines", International Journal of Machine Tools and Manufacture, Vol. 50, pp. 335-343, 2010

[19] J. Agapiou, E. Rivin, C. Xie, "Tool holder/spindle interfaces for cnc machine tools", CIRP Annals, Manufacturing Technology, Vol. 44, No. 1, pp. 383-387, 1995

[20] T. L. Schmitz, G. S. Duncan, "Three-component receptance coupling substructure analysis for tool point dynamics prediction", Journal of Manufacturing Science and Engineering, Vol. 127, No. 4, pp. 781-790, 2005

[21] T. L. Schmitz, M. A. Davies, M. D. Kennedy, "Tool point frequency response prediction for high-speed machining by RCSA", Journal of Manufacturing Science and Engineering, Vol. 123, No. 4, pp. 700-707, 2001

[22] M. Namazi, Y. Altintas, T. Abe, N. Rajapakse, "Modeling and identification of tool holder-spindle interface dynamics", International Journal of Machine Tools and Manufacture, Vol. 47, No. 9, pp. 13331341,2007

[23] K. Ahmadi, H. Ahmadian, "Modelling machine tool dynamics using a distributed parameter tool-holder joint interface", International Journal of Machine Tools and Manufacture, Vol. 47, No. 12-13, pp. 1916-1928, 2002

[24] E. Budak, A. Erturk, H. N. Ozguven, "A modeling approach for analysis and improvement of spindle-holder-tool assembly dynamics", CIRP Annals - Manufacturing Technology, Vol. 55, No. 1, pp. 369-372, 2006

[25] X. J. Xuan, Z. H. Haung, K. D. Wu, J. P. Hung, "Prediction of the frequency response function of a tool holder-tool assembly based on receptance coupling method", Engineering, Technology \& Applied Science Research, Vol. 8, No. 6, pp. 3555-3560, 2018

[26] A. Erturk, H. N. Ozguven, E. Budak, "Analytical modeling of spindletool dynamics on machine tools using Timoshenko beam model and receptance coupling for the prediction of tool point FRF", International Journal of Machine Tools and Manufacture, Vol. 46. No. 15, pp. 19011912, 2006 